\title{
MicroRNA-383-5p acts as a prognostic marker and inhibitor of cell proliferation in lung adenocarcinoma by cancerous inhibitor of protein phosphatase $2 \mathrm{~A}$
}

\author{
SHASHA ZHAO, XINYUAN GAO, SHUZHI ZANG, YUNXIA LI, XIANJUN FENG and XIAOMEI YUAN \\ Department of Respiratory Medicine, The First Hospital Affiliated to The Xinxiang Medical College, \\ Xinxiang, Henan 453100, P.R. China
}

Received November 12, 2015; Accepted April 24, 2017

DOI: $10.3892 / 01.2017 .6603$

\begin{abstract}
Lung cancer is the leading cause of cancer-associated mortality worldwide. MicroRNAs (miRNAs/miRs) serve a role in the occurrence and development of lung cancer. The aim of the present study was to analyze the expression and function of the proliferation-associated miR-383-5p in lung adenocarcinoma (LAC). Samples of human LAC and matched adjacent normal lung tissues were surgically removed, and miR-383-5p expression and the pathological characteristics of lung adenocarcinoma were investigated. The present study revealed that miR-383-5p expression level was significantly decreased in LAC tissues and its expression levels were markedly associated with tumor size and differentiation. Overexpression of miR-383-5p in A549 and H1299 LAC cell lines inhibited cell proliferation by $\mathrm{G}_{1}$ cell cycle phase arrest and induction of apoptosis. Cancerous inhibitor of protein phosphatase 2A (CIP2A), a potential target gene of miR-383-5p, was inversely associated with miR-383-5p expression level in LAC tissues and cell lines. Furthermore, the results of the present study demonstrated that CIP2A was directly regulated by miR-383-5p and the restoration of CIP2A expression reversed the inhibitory effects of miR-383-5p on LAC cell proliferation. In conclusion, the results of the present study demonstrated that miR-383-5p was downregulated in LAC tissues. By targeting CIP2A, miR-383-5p exerts its anti-proliferative function in LAC, suggesting its use a potential novel potential prognostic biomarker and therapeutic target for LAC.
\end{abstract}

\footnotetext{
Correspondence to: Dr Xiaomei Yuan, Department of Respiratory Medicine, The First Hospital Affiliated to The Xinxiang Medical College, 88 Jiankang Road, Weihui, Xinxiang, Henan 453100, P.R. China

E-mail: xiaomeiyuan1227@qq.com
}

Key words: microRNA-383-5p, lung adenocarcinoma, cancerous inhibitor of protein phosphatase $2 \mathrm{~A}$, proliferation

\section{Introduction}

Lung cancer is the most common type of malignant cancer with the highest mortality rate worldwide (1). In China, approximately 300,000 new lung cancer patients and more than 250,000 mortalities associated with lung cancer are predicted annually (2). Lung adenocarcinoma (LAC) is the most common type of lung cancer, accounting for $\sim 40 \%$ of cases (3). Despite recent advances in diagnosis, chemotherapy and targeted therapy, the overall survival rate of patients with LAC remains low at an advanced stage (5-year overall survival rate varies from $70 \%$ in stage IA to $25 \%$ in stage IIIA) (4). Currently, the most effective therapy for LA is complete surgical resection. However, a large number of patients with LAC have advanced stage IIIB or IV disease when first diagnosed (3). Thus, the elucidation of the molecular mechanisms underlying the tumorigenicity of LAC is essential for the development of novel treatments for this disease.

MicroRNAs (miRNAs/miRs) are a class of endogenous single-stranded short non-coding RNAs that silence target mRNAs by base-pairing with the 3'-untranslated region (3'UTR) of target genes in order to mediate translational repression and mRNA degradation (5). It has been reported that miRNAs may regulate $>50 \%$ of all human protein-coding genes expressions and serve an important role in various biological processes, including cell differentiation, metabolism, proliferation, apoptosis and tumorigenesis (6-8). It has been demonstrated that dysregulation of specific miRNAs contributes to the development and progression of cancer, including LAC cancer (9). Furthermore, miRNAs are markedly implicated in multiple steps of LAC occurrence and development, including proliferation, recurrence and metastasis, and miRNA-targeted treatment approaches have revealed marked potential in controlling the advanced stage of LAC (10-12).

The aim of the present study was to investigate the biological function of miR-383-5p in LAC. The expression profile of miR-383-5p and its clinicopathological characteristics was analyzed in patients with LAC. Subsequently, the effect of miR-383-5p on proliferation, cell cycle and apoptosis in LAC cells was observed. The results demonstrated that miR-383-5p suppresses the proliferation by directly targeting cancerous inhibitor of protein phosphatase 2A (CIP2A) in LAC. 


\section{Materials and methods}

Patients and tissue samples. Paired human LAC samples and adjacent normal tissues ( $\geq 3 \mathrm{~cm}$ away from the tumor) were obtained from 72 patients (male $=40$; female $=32$; average age, $43.79 \pm 6.33$; range $35-61$ years) who received surgical resection between January 2013 and May 2014 at the Department of Respiratory, The First Hospital Affiliated to the Xinxiang Medical College (Weihui, China). All surgical specimens were snap-frozen in liquid nitrogen and stored at $-80^{\circ} \mathrm{C}$ following resection until RNA extraction was performed. All patients did not receive chemotherapy or radiotherapy prior to surgery. The diagnoses of these tissue samples were confirmed by pathologists in The First Hospital Affiliated to the Xinxiang Medical College. Written informed consent was obtained from all patients prior to enrolment in the present study the study protocol was approved by the Ethics Committee of The First Hospital Affiliated to the Xinxiang Medical College.

Reverse transcription-quantitative polymerase chain reaction $(R T-q P C R)$ for miRNA. Total RNA from fresh tissues was isolated using an RNA Extraction Kit (Qiagen, Inc., Valencia, CA, USA), according to the manufacturer's protocol. Complementary DNA was obtained using specific miRNA primers for miR-383-5p (reverse transcription primer: 5'-GTCGTATCC AGTGCGTGTCGTGGAGTCGGCAATTGCACTGGATACGAC AGCCAC-3'; protocol: $30 \mathrm{~min}$ at $16^{\circ} \mathrm{C}, 30 \mathrm{~min}$ at $42^{\circ} \mathrm{C}$, and 5 min at $85^{\circ} \mathrm{C}$ ) Applied Biosystems; Thermo Fisher Scientific, Inc., Waltham, MA, USA) using the miScript Reverse Transcription Kit (Qiagen, Inc.). The expression level of miR-383-5p was quantified using miRNA specific TaqMan miRNA Assay kit (Applied Biosystems; Thermo Fisher Scientific, Inc.). qPCR was performed using the SYBR PCR Master Mix (Applied Biosystems; Thermo Fisher Scientific, Inc.) and ABI 7500 Fast (Applied Biosystems; Thermo Fisher Scientific, Inc.). PCR was performed as follows: 25 cycles of $10 \mathrm{~min}$ at $98^{\circ} \mathrm{C}, 10 \mathrm{sec}$ at $98^{\circ} \mathrm{C}, 10 \mathrm{sec}$ at $55^{\circ} \mathrm{C}$ and $20 \mathrm{sec}$ at $72^{\circ} \mathrm{C}$, with a final extension at $72^{\circ} \mathrm{C}$ for $5 \mathrm{~min}$. The PCR primers used were as follows: miR-383-5p forward, 5'-GGGAGATCAGAAGGTGATTGT GGCT-3' and reverse, 5'-CAGTGCGTGTCGTGGAGT-3'; U6 forward, 5'-CTCGCTTCGGCAGCACA-3' and reverse, 5'-AACGCTTCACGAATTTGCGT-3'. The relative quantification of miR-383-5p was determined using the $2^{-\Delta \Delta C q}$ method (13), with U6 small nuclear (sn)RNA used as the endogenous control to normalize the data.

Cell culture. A549 and H1299 human lung adenocarcinoma cell lines were obtained from the American Type Culture Collection (Manassas, VA, USA) and grown in RPMI-1640 medium (Invitrogen; Thermo Fisher Scientific, Inc.) supplemented with $10 \%$ fetal bovine serum (Thermo Fisher Scientific, Inc.) and $100 \mathrm{U} / \mathrm{ml}$ penicillin/streptomycin (Invitrogen; Thermo Fisher Scientific, Inc.) in a $37^{\circ} \mathrm{C}$ humidified incubator containing $5 \%$ $\mathrm{CO}_{2}$.

RNA oligonucleotide and cell transfection. The miR-383-5p mimic and control miRNA mimic were purchased from Shanghai GenePharma Co., Ltd. (Shanghai, China). The cells were treated with $50 \mathrm{nM}$ GMR-miR ${ }^{\mathrm{TM}}$ mixed with the miRNA mimic $(30 \mathrm{nM})$ using Lipofectamine ${ }^{\mathrm{TM}} 2000$ reagent
(Invitrogen; Thermo Fisher Scientific, Inc.), according to the manufacturer's protocol, when the density of cells was $<70 \%$. All the assays were performed $48 \mathrm{~h}$ after transfection.

$\left[{ }^{3} H\right]$ thymidine incorporation assay. A549 and H1299 cells were plated onto 24 -well plates at a density of $\sim 1 \times 10^{4}$ cells/well. Cells were serum-starved for $12 \mathrm{~h}$ at $37^{\circ} \mathrm{C}$ followed by addition of serum and $\left[{ }^{3} \mathrm{H}\right]$ thymidine $(2 \mathrm{Ci} / \mathrm{mM})$ for $4 \mathrm{~h}$. Subsequently, the cells were fixed in $0.3 \mathrm{ml} 10 \%$ trichloroacetic acid and lysed in $100 \mu 10.2 \mathrm{M} \mathrm{NaOH} / 0.2 \%$ SDS for $10 \mathrm{~min}$ at $25^{\circ} \mathrm{C}$. The radioactivity was detected using a liquid scintillation counting system (Beckman Coulter, Inc., Brea, CA, USA).

Cell cycle analysis. A total of $1 \times 10^{6}$ A549 or H1299 cells were harvested, washed with ice-cold PBS and fixed in $70 \%$ ice-cold ethanol at $4^{\circ} \mathrm{C}$ overnight. The fixed cells were washed with PBS and resuspended in $1 \mathrm{ml}$ PBS supplemented with $100 \mu \mathrm{g} / \mathrm{ml}$ bovine pancreatic RNase A (Sigma-Aldrich; Merck KGaA, Darmstadt, Germany) and $40 \mu \mathrm{g} / \mathrm{ml}$ propidium iodide (PI; Sigma-Aldrich; Merck KGaA) for 30 min at $4^{\circ} \mathrm{C}$, cell cycle analysis was performed with a Becton Dickinson FACSCalibur cytometer (BD Biosciences, Inc., Franklin Lakes, NJ, USA). Cell cycle analysis was performed using ModFit software (version 3.2.1, Verity Software House, Topsham, ME, USA).

Apoptosis assay. Cell apoptosis were detected using the Annexin V-Fluorescein Isothiocyanate (FITC) Apoptosis kit (Merck KGaA), according to the manufacturer's protocol. Briefly, cells were washed with ice-cold PBS and incubated in $500 \mu 1$ ice-cold $1 \mathrm{X}$ binding buffer containing $2.3 \mathrm{ml}$ Annexin V-FITC for $10 \mathrm{~min}$ at $4^{\circ} \mathrm{C}$, followed by $10 \mathrm{~min}$ of incubation at room temperature in the dark. Subsequently, all cells were resuspended in $500 \mathrm{ml}$ ice-cold $1 \mathrm{X}$ binding buffer supplemented with $5 \mathrm{ml}$ PI at room temperature for 15 min. Annexin V-FITC and PI signals were detected using a flow cytometer (FACSCalibur ${ }^{\mathrm{TM}}$;BD Biosciences, San Jose, CA, USA).

Western blot assays. Total protein lysates were extracted using radioimmunoprecipitation assay lysis buffer (Sigma-Aldrich; Merck KGaA) at $4^{\circ} \mathrm{C}$ for 30 min and detected using a bicinchoninic acid kit (Pierce; Thermo Fisher Scientific, Inc.). Protein $(30 \mu \mathrm{g})$ was separated by $10 \%$ SDS-PAGE and transferred onto polyvinylidene difluoride membranes. Subsequently the membranes were blocked by 5\% BSA (Sigma-Aldrich, Merck $\mathrm{KGaA}$ ) at room temperature for $1 \mathrm{~h}$, washed with TBST 3 times and then probed with primary antibodies against the following: CIP2A (cat no. NB110-59722; dilution, 1:1,000; duration, $4^{\circ} \mathrm{C}$ overnight, Novus Biologicals, LLC, Littleton, CO, USA) and GAPDH (cat. no. 5174; dilution, 1:2,000; duration, $4^{\circ} \mathrm{C}$ overnight; Cell Signaling Technology, Inc., Danvers, MA, USA), which was used as a control. The membranes were washed 3 times with TBST and incubated with horseradish peroxidase-linked secondary goat anti-rabbit antibody (cat. no. 1662408; dilution, 1:3,000; duration, $37^{\circ} \mathrm{C}$ for $1 \mathrm{~h}$; Bio-Rad Laboratories, Inc., Hercules, CA, USA). The bands were visualized using an enhanced chemiluminescence detection reagent by the ChemiDoc XRS system (Bio-Rad Laboratories, Inc.). 
Immunohistochemistry assay. For the immunohistochemistry assay, $10 \%$ formalin-fixed paraffin-embedded tissue sections (5 $\mu \mathrm{m}$ thick) were deparaffinized and rehydrated in graded alcohol $(50,65,75,85,95$ and 100\%) at room temperature for $1 \mathrm{~h}$. An endogenous antigen-retrieval procedure was performed using $10 \mathrm{mM}$ citrate buffer, $\mathrm{pH} 6.0$, at $95^{\circ} \mathrm{C}$ for $10 \mathrm{~min}$. Subsequently, slides were washed with PBS and incubated with primary antibodies at $4{ }^{\circ} \mathrm{C}$ in a humidified chamber overnight. The primary anti-CIP2A monoclonal antibody (cat. no. NB110-59722; dilution, 1:400; Novus Biologicals, LLC) were incubated at $4^{\circ} \mathrm{C}$ overnight. This was followed by incubation with biotinylated goat anti-rabbit serum IgG (cat. no. 21537; dilution, 1:500; Novus Biologicals, LLC, Littleton, CO, USA). Subsequently, the antigen-antibody reaction was visualized using diaminobenzidine serving as the chromogen under an Olympus CX41 microscope and counted in 5 high-power fields (magnification, x200).

Plasmid construction. The 3'UTR region of CIP2A was amplified from human genomic DNA and inserted into the pmirGLO vector (Promega Corporation, Madison, WI, USA) with HindIII and EcoRI restriction sites at the $3^{\prime}$ end of the luciferase gene in order to construct the luciferase reporter plasmids. For sequence point mutation, site-directed mutagenesis of potential target sites in the CIP2A 3'UTR were performed using a QuikChange Site-Directed Mutagenesis kit (Promega). The CIP2A recombinant plasmid (lacking 3'UTR) was amplified by PCR with the following primers: Forward, 5'-CTGCCATCATGCCGATGTTCAT-3' and reverse, 5'-CGG CTCTTAGGCGAAGGTG-3' and the PrimeSTAR GXL DNA Polymerase (Takara Biotechnology Co., Ltd., Dalian, China). PCR thermocycling conditions were as follows: 30 cycles of $30 \mathrm{sec}$ at $98^{\circ} \mathrm{C}, 90 \mathrm{sec}$ at $56^{\circ} \mathrm{C}$ and $45 \mathrm{sec}$ at $72^{\circ} \mathrm{C}$ with a final extension at $72^{\circ} \mathrm{C}$ for $5 \mathrm{~min}$. A LightCycler ${ }^{\circledR}$ instrument (Roche Diagnostics GmbH, Mannheim, Germany) was used for the PCR. The resulting PCR amplicons of CIP2A were cloned into the $\mathrm{T}$ vector (Promega). The correct clones were confirmed by sequencing.

miRNA target prediction. The following online miRNA target prediction algorithms were used to evaluate the potential target genes of miR-383-5p: TargetScan 6.2 database (http://www. targetscan.org/vert_71/). The target prediction runs were performed with a context percentile of $95 \%$ and a conserved method (14). The list of potential target gene and binding site was available by searching its database.

Luciferase assays. For the luciferase reporter assay, A549 and H1299 cells were seeded into a 24-well plate at density of $10^{5}$ and co-transfected with $50 \mathrm{nM}$ miR-338-5p mimic or control mimic and $200 \mathrm{ng}$ reporter recombinant plasmid using Lipofectamine $^{\mathrm{TM}} 2000$ reagent (Invitrogen; Thermo Fisher Scientific, Inc.), according to the manufacturer's protocol. At $48 \mathrm{~h}$ after transfection, luciferase activity was determined using a dual-luciferase system kit (Promega). Firefly luciferase activity was normalized against Renilla luciferase gene activity.

Statistical analysis. Data analyses were performed using SPSS software (version 15.0; SPSS, Inc., Chicago, IL, USA).
Table I. Clinical association of miR-383-5p expression in lung adenocarcinoma.

\begin{tabular}{|c|c|c|c|c|}
\hline \multirow[b]{2}{*}{ Group } & \multirow{2}{*}{$\begin{array}{c}\text { No. of } \\
\text { patients }\end{array}$} & \multicolumn{2}{|c|}{$\begin{array}{c}\text { Relative } \\
\text { miR-383-5p } \\
\text { expression level }\end{array}$} & \multirow[b]{2}{*}{ P-value } \\
\hline & & Low & High & \\
\hline Paraneoplastic tissues & 72 & 23 & 49 & 0.0025 \\
\hline Carcinoma tissue & 72 & 42 & 30 & \\
\hline Sex & & & & 0.6356 \\
\hline Male & 40 & 22 & 18 & \\
\hline Female & 32 & 15 & 17 & \\
\hline Age, years & & & & 1.0000 \\
\hline$>65$ & 39 & 18 & 21 & \\
\hline$\leq 65$ & 33 & 15 & 18 & \\
\hline Size of carcinoma, $\mathrm{cm}$ & & & & 0.0309 \\
\hline$>3$ & 29 & 18 & 11 & \\
\hline$\leq 3$ & 43 & 15 & 28 & \\
\hline TNM stage & & & & 0.2381 \\
\hline I-II & 35 & 15 & 20 & \\
\hline III-IV & 37 & 22 & 15 & \\
\hline Degree of differentiation & & & & 0.0299 \\
\hline Well and moderately & 43 & 16 & 27 & \\
\hline Poorly & 29 & 19 & 10 & \\
\hline Lymph node metastasis & & & & 1.000 \\
\hline Negative & 31 & 17 & 14 & \\
\hline Positive & 41 & 23 & 18 & \\
\hline Distant metastasis & & & & 0.6376 \\
\hline Negative & 37 & 17 & 20 & \\
\hline Positive & 35 & 19 & 16 & \\
\hline
\end{tabular}

Differences between variables were assessed by the Fisher's exact test. miR, microRNA; TNM, tumor-node-metastasis.

Results are presented as the mean \pm standard deviation. Differences between two groups were tested by Student's t-test, and differences among three or more groups were measured by one-way analysis of variance. Count data were analyzed using Fisher's exact tests. Univariate survival analysis was performed using the Kaplan-Meier estimator method and the log-rank test. $\mathrm{P}<0.05$ was considered to indicate a statistically significant difference.

\section{Results}

Associations between miR-383-5p expression level and clinicopathological features of lung adenocarcinoma. The expression levels of miR-383-5p in 72 LAC tissues and adjacent non-tumorous tissues were determined using RT-qPCR. The associations of miR-383-5p expression level with various clinicopathological parameters of patients with LAC are summarized in Table I. These results indicated that miR-383-5p was significantly downregulated in 58.3\% (42/72) 
A

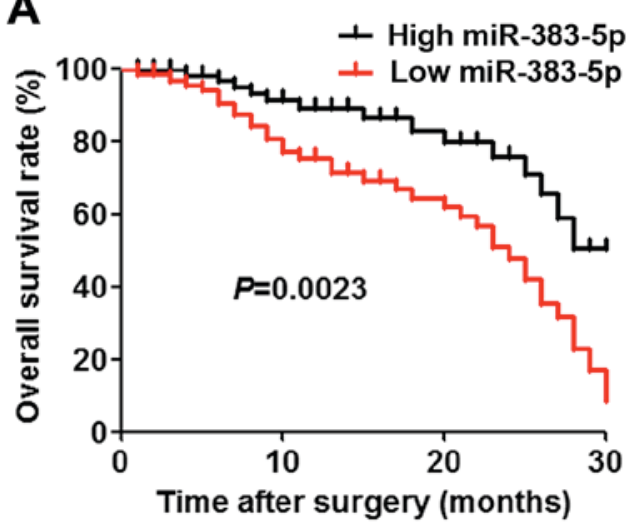

B

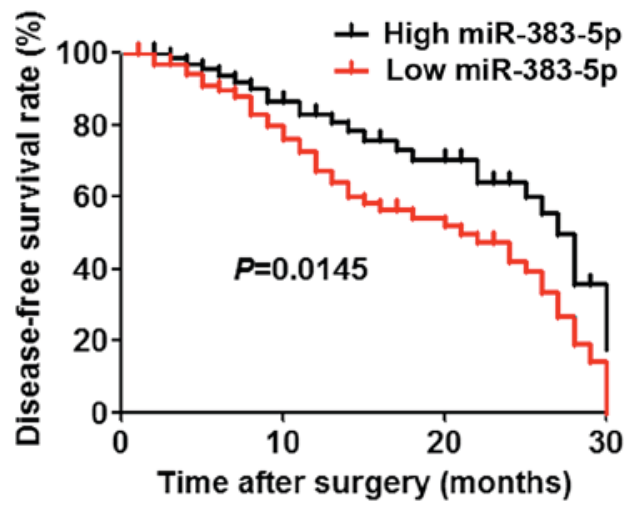

Figure 1. Kaplan-Meier estimator curves of survival time in patients with lung adenocarcinoma were separated into groups according to miR-383-5p expression levels. (A) Overall survival rate. (B) Disease-free survival rate. miR, microRNA.
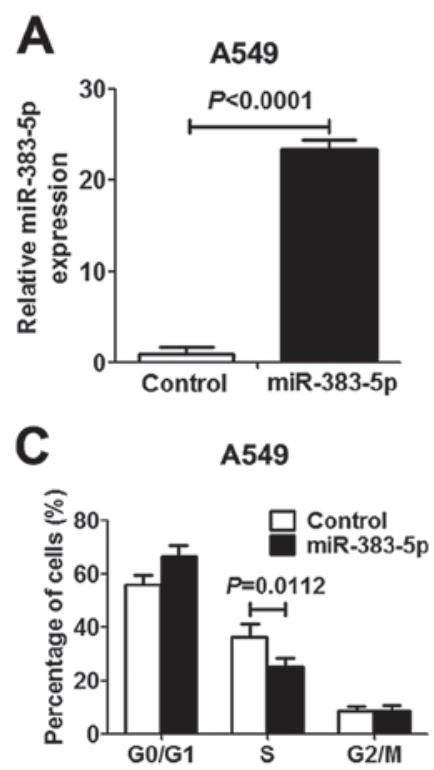
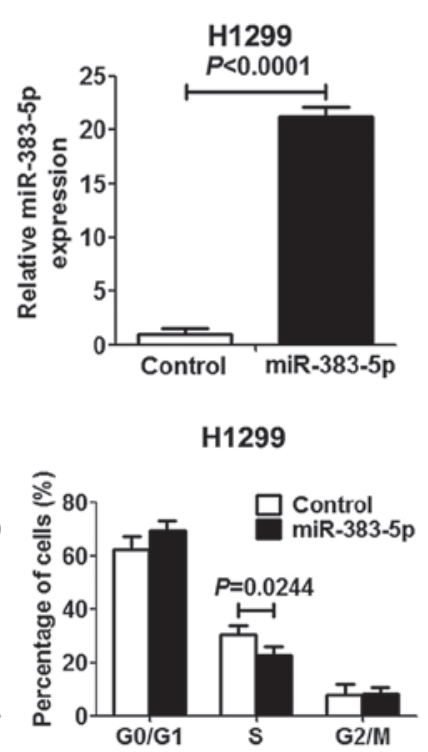

B
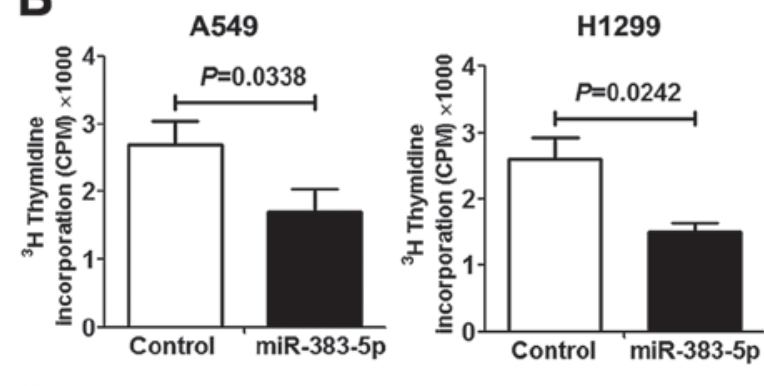

D
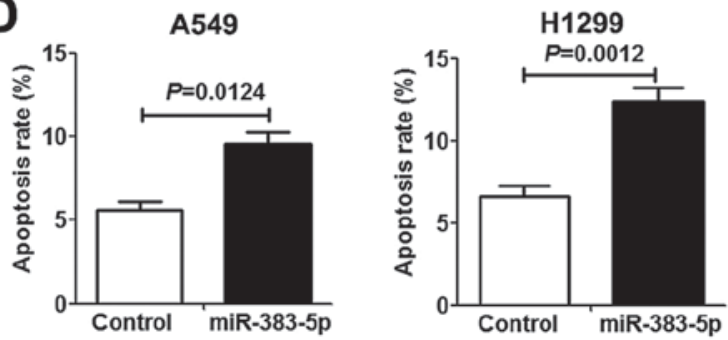

Figure 2. Effects of the miR-383-5p expression level on proliferation $48 \mathrm{~h}$ after transient transfection with miR-383-5p mimic (or control mimic) in lung adenocarcinoma cells. (A) Validation of miR-383-5p expression level in A549 and H1299 cells using the reverse transcription-quantitative polymerase chain reaction. (B) $\left[{ }^{3} \mathrm{H}\right]$ thymidine incorporation assays were performed to examine cell proliferation $48 \mathrm{~h}$ after transfection. (C) Frequencies of cells at various stages of the cell cycle. (D) The proportion of apoptotic cells (Annexin V-fluorescein isothiocyanate, positive; propidium iodide, negative). Data are expressed as the mean \pm standard deviation. $\mathrm{n}=5$. miR, microRNA.

of the LAC tissues examined in comparison with the matched adjacent non-cancerous tissues, $31.9 \%$ (23/72), from the same patients. The results demonstrated that there were significant associations between miR-383-5p downregulation and unfavorable variables, including tumor size $(\mathrm{P}=0.0309)$ and differentiation $(\mathrm{P}=0.0299)$. Furthermore, patients with low miR-383-5p expression levels had a significantly decreased overall survival and disease-free survival rate compared with those with high miR-383-5p expression levels (Fig. 1A and B).

miR-383-5p inhibits proliferation and induces apoptosis in LAC cells. In order to investigate the role of miR-383-5p in human LAC proliferation and apoptosis, miR-383-5p was overexpressed in human A549 and H1299 LAC cells by transfection with an miR-383-5p mimic. The expression level of miR-383-5p in transfected cells revealed a significant increase compared with transfected control cells, which indicated that mir-383-5p was successfully transfected into LAC cells (Fig. 2A). $\left[{ }^{3} \mathrm{H}\right]$ thymidine incorporation assays and miR-383-5p overexpression significantly inhibited A549 and H1299 cell proliferation (Fig. 2B). To further elucidate the anti-proliferative mechanism underlying miR-383-5p in LAC cells, the cell cycle and apoptosis were analyzed. As presented in Fig. 2C and D, miR-383-5p overexpression in LAC cells significantly increased the proportion of cells in the $G_{0} / G_{1}$ cell cycle phase and decreased the proportion of cells in $\mathrm{S}$ phase compared with the control group. Furthermore, promotion of cell apoptosis was observed in LAC cells following transfection with miR-383-5p.

miR-383-5p directly targets CIP2A in LAC cells. Using open access software TargetScan 6.2 database (http://www. 
A

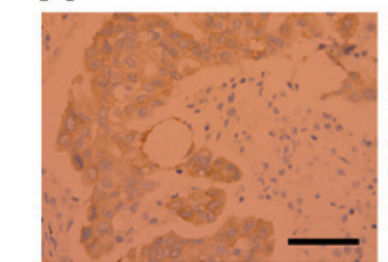

High miR-383-5p

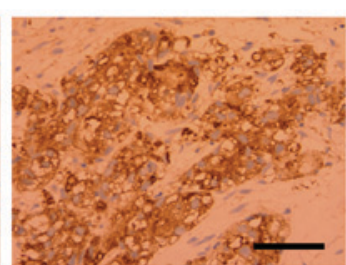

Low miR-383-5p

C

WT CIP2A 3'UTR $\quad$ 5'......AAUUUAGUAAAGACCCUGAUCUG......3'

miR-383-5p 3'.....UCGGUGUUAGUGGAAGACUAGAC...... '

Mut CIP2A 3'UTR

miR-383-5p
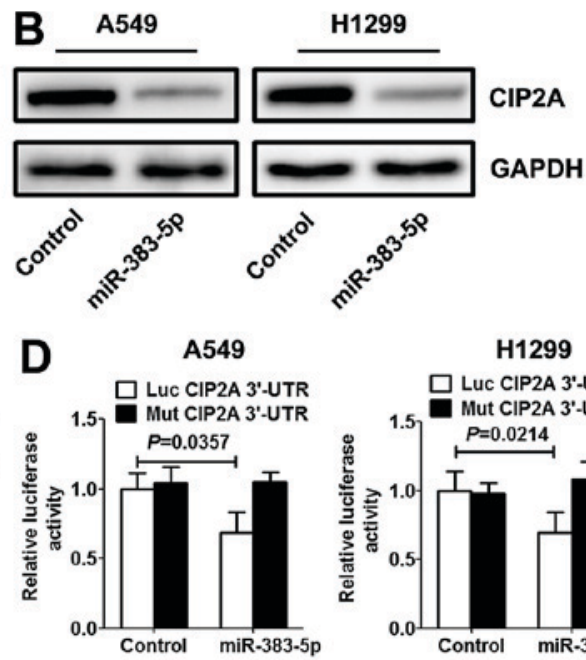

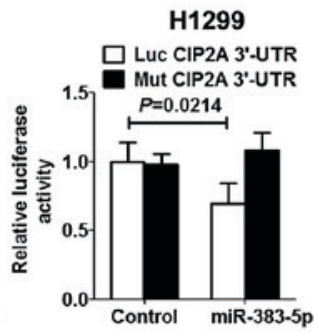

Figure 3. miR-383-5p directly targets CIP2A by binding to its 3'UTR. (A) Immunohistochemistry demonstrated an inverse association between the expression levels of miR-383-5p and CIP2A in LAC tissue samples (scale bars, $100 \mu \mathrm{m}$ ). (B) Western blot analysis of CIP2A protein expression levels in LAC cells transfected with miR-383-5p mimic (or control mimic). (C) miR-383-5p and its putative binding sequence in the 3'UTR of CIP2A (lines indicate matching base pairs and crosses represent non-matching base pairs). (D) Dual-luciferase reporter analysis was performed in LAC cells that were co-transfected with miR-383-5p mimic (or control mimic) and reporter vectors carrying CIP2A 3'UTR with wild-type compared with mutated miR-383-5p response element. Data are expressed as the mean \pm standard deviation. $\mathrm{n}=5$. miR, microRNA; UTR, untranslated region; CIP2A, cancerous inhibitor of protein phosphatase $2 \mathrm{~A} ; \mathrm{LAC}$, lung adenocarcinoma; WT, wild-type; Mut, mutant.

A
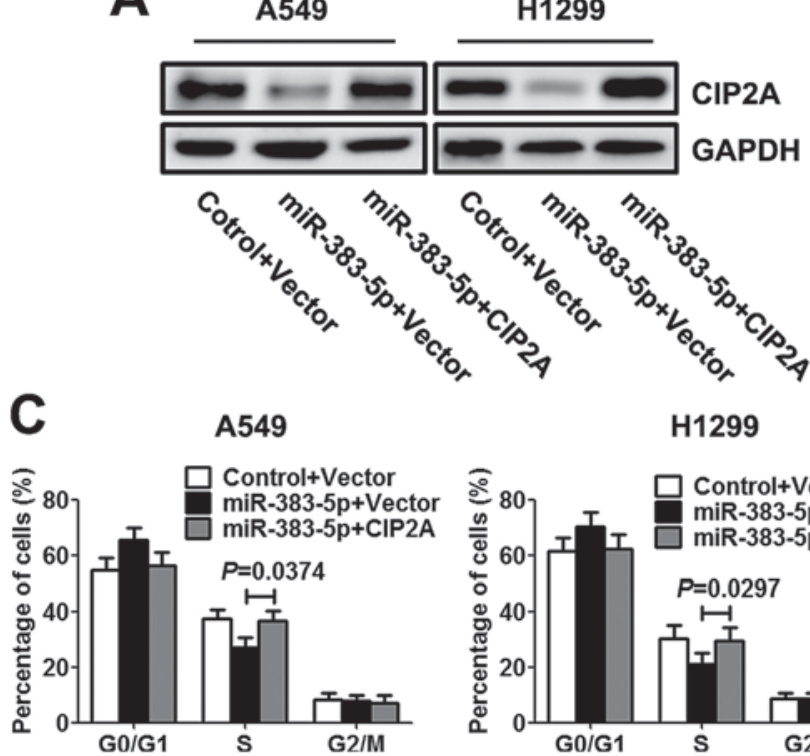

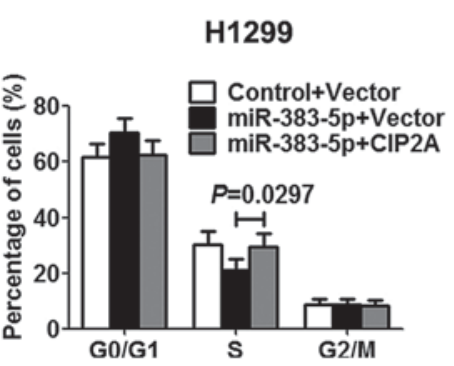

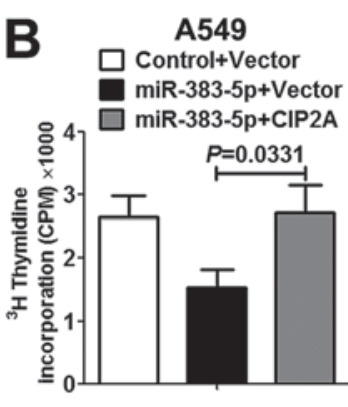

A549

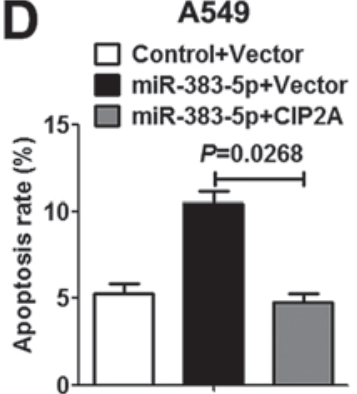

H1299

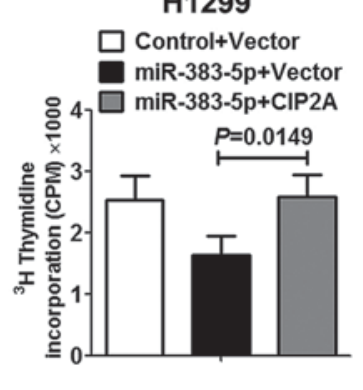

H1299

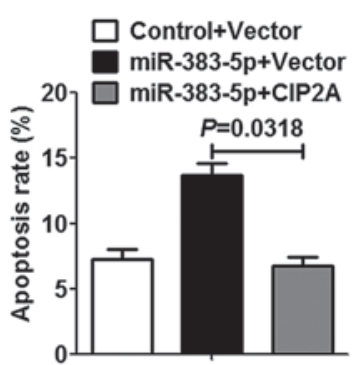

Figure 4. Re-expression of CIP2A reverses the inhibitory effect of miR-383-5p on cell proliferation. Lung adenocarcinoma cells were co-transfected with miR-383-5p mimic (or control mimic) and CIP2A recombinant plasmid (or empty vector) for $48 \mathrm{~h}$. (A) Expression level of CIP2A protein was analyzed by western blotting. (B) Cell proliferation ability was examined using a $\left[{ }^{3} \mathrm{H}\right]$ thymidine incorporation assay. (C) Cell cycle progression and (D) apoptosis were analyzed by flow cytometry. Data are expressed as the mean \pm standard deviation. $n=5$. CIP2A, cancerous inhibitor of protein phosphatase $2 \mathrm{~A}$; miR, microRNA.

targetscan.org/vert_71/), CIP2A was selected as a preferred candidate target gene of miR-383-5p. Immunohistochemistry analysis demonstrated that the expression levels of CIP2A in LAC with high miR-383-5p expression levels were significantly decreased compared with those with low miR-383-5p expression level (Fig. 3A). Western blotting revealed that miR-383-5p mimic significantly decreased the expression level of CIP2A protein in LAC cells (Fig. 3B). A target prediction program (TargetScan) was used to identify putative miRNA-binding sites in the 3 'UTR of CIP2A. The potential wild-type and mutant CIP2A 3'UTR fragment were cloned into a luciferase reporter gene system (Fig. 3C). LAC cells were co-transfected with a vector containing wild-type/mutant 3 'UTR of CIP2A and miR-383-5p mimic (or control mimic). Overexpression of miR-383-5p in the two LAC cell lines induced a significantly decreased luciferase activity for wild-type, whereas no alteration in luciferase activity was detected with the mutant CIP2A 3'UTR luciferase reporter plasmid (Fig. 3D). 
Upregulation of CIP $2 A$ reverses the effects of miR-383-5p on proliferation. To further investigate miR-383-5p repression of LAC cell proliferation mediated by CIP2A, A549 and H1299 cells were co-transfected with miR-383-5p mimic (or control mimic) with CIP2A constructs lacking the respective 3'UTR or empty vector. Western blotting was performed to evaluate the expression levels of CIP2A protein. As presented in Fig. 4A, the co-transfection rescued the decreased expression level of CIP2A protein in LAC cells that was induced by miR-383-5p. Additionally, restoration of CIP2A expression level reversed the inhibitory effects of exogenous miR-383-5p on proliferation, resulting in a significant increase in DNA synthesis (Fig. 4B). Similarly, re-expression of CIP2A exhibited an apparent rescued $\mathrm{S}$ cell cycle phase and decreased the apoptosis rate in LAC cells (Fig. 4C and D).

\section{Discussion}

According to previous studies, miRNAs may offer a novel regulatory mechanism of gene expression, and miRNAs may act as either oncogenes or tumor suppressors in light of the biological function of their target genes (15-19). It has been suggested that miRNA expression levels are associated with specific clinical characteristics of cancer, thus they can be used to classify normal and cancerous tissues, as well as to predict prognosis (20). Recent studies have revealed that dysregulation of miR-383 is associated with various malignancies, including hepatocellular carcinoma (21), pancreatic cancer (22), glioma (23), testicular embryonal carcinoma (24) and medulloblastoma (25).

Our results demonstrated that the expression level of miR-383-5p was decreased in LAC, and the expression level of miR-383-5p was associated with tumor size and differentiation, suggesting that miR-383-5p may be associated with tumorigenesis of LAC. Furthermore, patients with low expression levels of miR-383-5p had decreased overall and disease-free survival rates. The results of the present study identified that miR-383-5p was an independent prognostic marker for predicting overall and disease-free survival of patients with LAC. The results of the present study suggested that the status of miR-383-5p was critical for progression of LAC. Overexpression of miR-383-5p in LAC cells suppressed proliferation by blocking $\mathrm{G}_{1}-\mathrm{S}$ transition and inducing apoptosis, suggesting that miR-383-5p acted as a tumor suppressor in LAC. Numerous studies have suggested that miR-383-5p inhibits tumor cell growth and functions as a negative regulator of proliferation $(24,26)$, and upregulation of miR-383 induces a inhibition of the transition from the $G_{0} / G_{1}$ phase to $S$ cell cycle phase (27). The results of the present study were consistent with those of previous studies demonstrating that miR-383-5p inhibits cell growth by blocking the $\mathrm{G}_{1}-\mathrm{S}$ cell cycle transition and inducing apoptosis.

miRNAs are known to control diverse biological processes via the regulation of target genes. Furthermore, the present study demonstrated that an inverse association between miR-383-5p and CIP2A expression levels was observed in LAC tissue samples, and revealed that the increased miR-383-5p expression level in LAC cells resulted in downregulation of the CIP2A protein expression level. Additionally, the present study searched the TargetScan database and demonstrated that CIP2A has a predicted binding site of miR-383-5p within its $3^{\prime}$ UTR. To verify whether CIP2A is a direct target of miR-383-5p in LAC cells, the luciferase reporter assay was performed and the data indicated that miR-383-5p was able to bind efficiently to the predicted miR-383-5p-binding site within the CIP2A 3'UTR. This phenomenon provided important evidence indicating a direct interaction between miR-383-5p and CIP2A.

CIP2A, also known as KIAA1524 and p90, is implicated as a human oncoprotein that promotes the stability of c-Myc protein and inhibits the degradation of c-Myc by inhibiting the protein phosphatase 2A-mediated dephosphorylation of Myc at $\operatorname{Ser}^{62}(28)$. A number of studies have documented that CIP2A serves an important role in cell proliferation (29), transformation (30), drug resistance (31) and maintenance of a malignant cellular phenotype (32). Furthermore, CIP2A status was a significant prognostic factor for patients with non-small cell carcinoma, and CIP2A protein expression levels were revealed to be overexpressed in human lung cancer samples and associated with poor survival rates (33). Previous studies have provided direct evidence that CIP2A may promote cell proliferation via the protein kinase $\mathrm{B}$ signaling pathway and protect the non-small cell lung cancer cells from apoptosis $(34,35)$. These results imply an oncogenic role for CIP2A. The present study verified that restoration of the CIP2A expression level abrogated the inhibitory effect of miR-383-5p on LAC cell proliferation, supporting evidence that CIP2A overexpression is a feature and may be a critical event that occurs in LAC carcinogenesis. Taken together, the results of the present study indicated that miR-383-5p exerts an inhibitory effect on LAC, at least in part, by inhibiting CIP2A.

In conclusion, the results of the present study indicated that downregulation of miR-383-5p is significantly associated with larger tumor size, lower differentiation degree and poor survival in patients with LAC. The results of the present study revealed novel insights into the molecular mechanisms by which miR-383-5p exerts its negative effects on cell proliferation in LAC cells by inhibition of CIP2A. This newly identified target of miR-383-5p may provide a novel therapeutic target and strategy for the treatment of patients with LAC.

\section{Acknowledgements}

The present study was supported by the Scientific and Technical Project of Henan Health Department (grant no. 200804056).

\section{References}

1. Jemal A, Bray F, Center MM, Ferlay J, Ward E and Forman D: Global cancer statistics. CA Cancer J Clin 61: 69-90, 2011.

2. She J, Yang P, Hong Q and Bai C: Lung cancer in China: Challenges and interventions. Chest 143: 1117-1126, 2013.

3. Wang H, Zhu LJ, Yang YC, Wang ZX and Wang R: MiR-224 promotes the chemoresistance of human lung adenocarcinoma cells to cisplatin via regulating $\mathrm{G}_{1} / \mathrm{S}$ transition and apoptosis by targeting p21(WAF1/CIP1). Br J Cancer 111: 339-354, 2014.

4. Yan G, Yao R, Tang D, Qiu T, Shen Y, Jiao W, Ge N, Xuan Y and Wang Y: Prognostic significance of microRNA expression in completely resected lung adenocarcinoma and the associated response to erlotinib. Med Oncol 31: 203, 2014.

5. Wang K, Liang Q, Wei L, Zhang W and Zhu P: MicroRNA-608 acts as a prognostic marker and inhibits the cell proliferation in hepatocellular carcinoma by macrophage migration inhibitory factor. Tumour Biol 37: 3823-3830, 2016. 
6. Hu J, Qiu M, Jiang F, Zhang S, Yang X, Wang J, Xu L and Yin R MiR-145 regulates cancer stem-like properties and epithelial-to-mesenchymal transition in lung adenocarcinoma-initiating cells. Tumour Biol 35: 8953-8961, 2014.

7. Johnnidis JB, Harris MH, Wheeler RT, Stehling-Sun S, Lam MH, Kirak O, Brummelkamp TR, Fleming MD and Camargo FD: Regulation of progenitor cell proliferation and granulocyte function by microRNA-223. Nature 451: 1125-1129, 2008.

8. Xing F, Wu K and Watabe K: MicroRNAs in cancer stem cells: New regulators of stemness. Curr Pharm Des 20: 5319-5327, 2014.

9. Qi J and Mu D: MicroRNAs and lung cancers: From pathogenesis to clinical implications. Front Med 6: 134-155, 2012.

10. Gu Y, Wang XD, Lu JJ, Lei YY, Zou JY and Luo HH: Effect of mir-16 on proliferation and apoptosis in human A549 lung adenocarcinoma cells. Int J Clin Exp Med 8: 3227-3233, 2015.

11. Arima C, Kajino T, Tamada Y, Imoto S, Shimada Y, Nakatochi M, Suzuki M, Isomura H, Yatabe Y, Yamaguchi $\mathrm{T}$, et al: Lung adenocarcinoma subtypes definable by lung development-related miRNA expression profiles in association with clinicopathologic features. Carcinogenesis 35: 2224-2231, 2014.

12. Chen DQ, Pan BZ, Huang JY, Zhang K, Cui SY, De W, Wang R and Chen LB: HDAC 1/4-mediated silencing of microRNA-200b promotes chemoresistance in human lung adenocarcinoma cells. Oncotarget 5: 3333-3349, 2014.

13. Livak KJ and Schmittgen TD: Analysis of relative gene expression data using real-time quantitative PCR and the 2(-Delta Delta C(T)) method. Methods 25: 402-408, 2001.

14. Riffo-Campos ÁL, Riquelme I and Brebi-Mieville P: Tools for Sequence-Based miRNA Target Prediction: What to Choose? Int J Mol Sci 17: pii: E1987, 2016.

15. Wang S, Zhao X, Wang J, Wen Y, Zhang L, Wang D, Chen H, Chen Q and Xiang W: Upregulation of microRNA-203 is associated with advanced tumor progression and poor prognosis in epithelial ovarian cancer. Med Oncol 30: 681, 2013.

16. Zhu K, Ding H, Wang W, Liao Z, Fu Z, Hong Y, Zhou Y, Zhang CY and Chen X: Tumor-suppressive miR-218-5p inhibits cancer cell proliferation and migration via EGFR in non-small cell lung cancer. Oncotarget 7: 28075-28085, 2016

17. Xiao P and Liu WL: MiR-142-3p functions as a potential tumor suppressor directly targeting HMGB1 in non-small-cell lung carcinoma. Int J Clin Exp Pathol 8: 10800-10807, 2015.

18. Li YQ, Lu JH, Bao XM, Wang XF, Wu JH and Hong WQ: MiR-24 functions as a tumor suppressor in nasopharyngeal carcinoma through targeting FSCN1. J Exp Clin Cancer Res 34: 130, 2015.

19. Yu T, Liu L, Li J, Yan M, Lin H, Liu Y, Chu D, Tu H, Gu A and Yao M: MiRNA-10a is upregulated in NSCLC and may promote cancer by targeting PTEN. Oncotarget 6: 30239-30250, 2015.

20. Xu F, Zhang H, Su Y, Kong J, Yu H and Qian B: Up-regulation of microRNA-183-3p is a potent prognostic marker for lung adenocarcinoma of female non-smokers. Clin Transl Oncol 16: 980-985, 2014

21. Chen L, Guan H, Gu C, Cao Y, Shao J and Wang F: miR-383 inhibits hepatocellular carcinoma cell proliferation via targeting APRIL. Tumour Biol 37: 2497-2507, 2016.

22. Han S, Cao C, Tang T, Lu C, Xu J, Wang S, Xue L, Zhang X and $\mathrm{Li} \mathrm{M}$ : ROBO3 promotes growth and metastasis of pancreatic carcinoma. Cancer Lett 366: 61-70, 2015.
23. He Z, Cen D, Luo X, Li D, Li P, Liang L and Meng Z: Downregulation of miR-383 promotes glioma cell invasion by targeting insulin-like growth factor 1 receptor. Med Oncol 30: 557, 2013.

24. Lian J, Tian H, Liu L, Zhang XS, Li WQ, Deng YM, Yao GD, Yin MM and Sun F: Downregulation of microRNA-383 is associated with male infertility and promotes testicular embryonal carcinoma cell proliferation by targeting IRF1. Cell Death Dis 1: e94, 2010.

25. Li KK, Pang JC, Lau KM, Zhou L, Mao Y, Wang Y, Poon WS and Ng HK: MiR-383 is downregulated in medulloblastoma and targets peroxiredoxin 3 (PRDX3). Brain Pathol 23: 413-425, 2013.

26. Lü M, Tian H, Cao YX, He X, Chen L, Song X, Ping P, Huang H and Sun F: Downregulation of miR-320a/383-sponge-like long non-coding RNA NLC1-C (narcolepsy candidate-region 1 genes) is associated with male infertility and promotes testicular embryonal carcinoma cell proliferation. Cell Death Dis 6: e1960,2015.

27. Xu Z, Zeng X, Tian D, Xu H, Cai Q, Wang J and Chen Q: MicroRNA-383 inhibits anchorage-independent growth and induces cell cycle arrest of glioma cells by targeting CCND1. Biochem Biophys Res Commun 453: 833-838, 2014

28. Liu N, He QM, Chen JW, Li YQ, Xu YF, Ren XY, Sun Y, Mai HQ, Shao JY, Jia WH, et al: Overexpression of CIP2A is an independent prognostic indicator in nasopharyngeal carcinoma and its depletion suppresses cell proliferation and tumor growth. Mol Cancer 13: 111, 2014

29. Zheng Z, Qiao Z, Chen W, Gong R, Wang Y, Xu L, Ma Y, Zhang L, $\mathrm{Lu}$ Y, Jiang B, et al: CIP2A regulates proliferation and apoptosis of multiple myeloma cells. Mol Med Rep 14: 2705-2709, 2016.

30. Liu Z, Ma L, Wen ZS, Cheng YX and Zhou GB: Ethoxysanguinarine induces inhibitory effects and downregulates CIP2A in lung cancer cells. ACS Med Chem Lett 5: 113-118, 2013.

31. Liu J, Wang M, Zhang X, Wang Q, Qi M, Hu J, Zhou Z, Zhang C, Zhang W, Zhao W and Wang X: CIP2A is associated with multidrug resistance in cervical adenocarcinoma by a P-glycoprotein pathway. Tumour Biol 37: 2673-2682, 2016.

32. Junttila MR, Puustinen P, Niemelä M, Ahola R, Arnold H, Böttzauw T, Ala-aho R, Nielsen C, Ivaska J, Taya Y, et al: CIP2A inhibits PP2A in human malignancies. Cell 130: 51-62, 2007.

33. Dong QZ, Wang Y, Dong XJ, Li ZX, Tang ZP, Cui QZ and Wang EH: CIP2A is overexpressed in non-small cell lung cancer and correlates with poor prognosis. Ann Surg Oncol 18: 857-865, 2011.

34. Chao TT, Wang CY, Lai CC, Chen YL, Tsai YT, Chen PT, Lin HI, Huang YC, Shiau CW, Yu CJ and Chen KF: TD-19, an erlotinib derivative, induces epidermal growth factor receptor wild-type nonsmall-cell lung cancer apoptosis through CIP2A-mediated pathway. J Pharmacol Exp Ther 351: 352-358, 2014.

35. Lei N, Peng B and Zhang JY: CIP2A regulates cell proliferation via the AKT signaling pathway in human lung cancer. Oncol Rep 32: 1689-1694, 2014. 